\title{
DESIGNING FOR TRUST IN EMERGING TECHNOLOGIES IN THE HEALTH SECTOR
}

\author{
Amalie Damsgaard JENSEN, Eline HÅKONSEN and Martina KEITSCH \\ Department of Design, Norwegian University of Science and Technology (NTNU)
}

\begin{abstract}
Design as an academic discipline requires a good deal of practice-based research and learning. To facilitate cross-pollination of design theory and practice, this article discusses the connection of a literature study and the development of a designer tool to employ theoretical insights in trust in emerging technologies in the health sector for practice. The ubiquitous spread of emerging technologies (ET) has created opportunities that profoundly impact sectors such as policymaking, administration, economy, science, and health sectors, and ET products, and systems services might alter society as a whole. The dilemma that while technologies are becoming smarter and more connected, they are seemingly getting more obscure and ambiguous too, raising some important questions related to trust. Considering that trust is a highly dynamic and complex phenomenon, for example considering aspects such as risk and uncertainty, this article sketches out how trust can be theoretically revisited and practically strengthened in situations, where both risk and uncertainty are bound to be involved. Following the introduction, the second part of the article investigates how trust in emerging technologies is reflected in current (design) literature and how its presence or lack can impact on an emergency response. The third part presents a design tool that facilitates to promote, integrate, and sustain trust. The conclusion in part 4 discussed the students' learning experiences on combining design research and practice in a master's course.
\end{abstract}

Keywords: Trust, emerging technologies, emergency health products and services

\section{INTRODUCTION}

Technology affects every aspect of life, society, and environment, and its development is constantly advancing and increasing in complexity. We have seen a boom of new and disruptive technologies, also known as emerging technologies, on the market, and it is predicted that these will impact almost every occupation within the next 10-20 years [1]. Everything is becoming smarter and more connected, and as a result, their opportunities, functionalities, and capabilities expand exponentially, way beyond traditional product boundaries [2]. Emerging technologies are creating many positive outcomes, such as healthcare technology improving patients' quality of life by predicting certain diseases with AI [3] or using blockchain to ensure that sensitive patient data is transferred securely between multiple parties [4]. However, given the increase of these technologies and the fact that their internal workings often are invisible and hard to comprehend, it is likely that trust in technology will change during the digital revolution.

\subsection{Methodological approach and background of the study}

The study presented in this article comprises a literature review and a practical project which are both parts of a master's course at the Department of Design at the Norwegian University of Technology in Trondheim (NTNU), Norway. The objectives of the course is to write a scientific article on a self-chosen topic to gain theoretical insights, to apply these insights in a project, which further explores the topic, and to present a design concept/solution. This article discusses literature trust concerning emerging technologies used in emergencies. Sources are reports, articles, and journals, that have been found mainly through Google Scholar, Scopus, and Oria. Keywords for the search were: Trust, digital trust, transparency, emerging technologies, health technology, and emergency technology. The project explored the practical side of conveying trust values and norms in emergency products. Author one and two worked with EGGs Design as partners and two supervisors from the Design Department at NTNU. The project resulted in a 'design-for-trust process' comprising a prototype of a workshop kit and an Instagram account for inspiration for designers. 


\section{TRUST, TECHNOLOGY TRUST AND TRUST IN EMERGENCY SITUATIONS}

Trust is a highly dynamic and subjective phenomenon and certainly connected to risk: both the nature of the risk and the willingness to take on said risk. Many researchers go as far as to say that trust is only required in situations that are characterized by risk [5]. So, when there is an immediate risk to health, life, property, or environment, it seems reasonable to say that trust is fundamental - whether it is trust in oneself and one's abilities, in colleagues, in the equipment, or technological devices remains an issue that the following section will explore. Researchers have widely explored the concept of trust for the past 50 years, examining its role and implications in society. There exist several characterizations of trust [6] and McKnight provides one of the most cited and robust definitions: "The willingness to take on risk and be vulnerable irrespective of the ability to control the outcome or trustee. All at once, it includes intentions, beliefs, behaviours, disposition, and institutions as part of a dynamic phenomenon which changes according to the nature of risk and interdependencies of a situation [7]."

Historically, most literature has focused on interpersonal, dispositional, institutional, and interorganizational trust, and the huge variety of definitions only contributes to the complexity of the concept. Technology trust relates to the belief that a product, service, or the underlying technology infrastructure performs accordingly to users and stakeholders' expectations and ideally adds value to the performance. Historically, most literature has focused on interpersonal, dispositional, institutional, and interorganizational trust, and the huge variety of definitions only contributes to the complexity of the concept. Technology trust relates to the belief that a product, service, or the underlying technology infrastructure performs accordingly to users and stakeholders' expectations and ideally adds value to the performance. According to McKnight et. al. trust involves among principles of [8]

Functionality: having the capabilities to do a task [14]

Usability: ease of use [15] [16] [17]

Effectiveness: provide help when needed [18]

Reliability: operate consistently without failing [19].

Yet, when making the choice of trusting a product, one also chooses to trust the humans who created said artifact, and a designer should also get familiar with different aspects of trust depending on the product, device, or service and on the context of its use. For technology to become a mediator of trust between people and/ or organizations [20] a designer must convey trust via products and services. To become an intermediary of trust, a designer needs an understanding of why it is important to consider trust in a design process and how to facilitate trust-building.

\subsection{Emerging products and trust}

Examples for emerging technologies, are artificial intelligence (AI), 3D printing, augmented reality (AR), virtual reality (VR), robotics, drones, internet of things (IoT), blockchain, biometrics, and nanotechnology. In emerging technologies, trust issues get more complex. Many of these technologies are being used as buzzwords in media and throughout society, yet few users understand what these technologies do, or can do in the future. They often fall under the category of "black box solutions" which is defined as a complex system or device whose internal workings are hidden or not readily understood [9]. In recent decades various guidelines for identifying trust requirements in design processes related to specific domains have been developed, such as e-commerce [11], mobile vendors [12], or for establishing trust in Virtual Healthcare Communities [13].

Emergency situations, where emerging technologies are used have specific trust requirements. An emergency is defined as a "serious, unexpected, and often dangerous situation requiring immediate action". Emerging products and services imply special challenges e.g., related to the acute and oftentimes chaotic scenes of the situation. Risk and uncertainty are bound to be involved, and this makes trust issues especially interesting for designers developing these products and services. In recent years researchers have investigated what influences trust in emerging technologies [10]. Both trust and accurate, accessible, and timely information are essential for the coordination of emergencies. Proper training combined with the skills and knowledge of all professionals involved in an emergency situation are important aspects for appropriate emergency response and a designer should be knowledgeable of these factors. 


\section{RESULTS}

The practice project lasted for 4 months and included approximately 50 participants, designers, peers, and supervisors from the department. It was connected to a specific emergency product, 'Insta-Patch'. Author 1 and 2 analysed the product related to the factors above and investigated the context of its use. Insta-Patch is an instant injury assessment and monitoring patch for fast and efficient patient monitoring outside the hospital. Insta-Patch enables the assessment of an injured or ill person's condition in any medical emergency and makes it possible to determine the priority of the patient's treatment, based on the severity of their condition - also known as triage. This product is in an early development stage and the inventors of lnsta-Patch were asking questions such as: 'Would you have dared more if a small patch from the first aid kit could tell you what condition the injured person is in?' This question indicates that daring to use this kind of patch to save lives has a comparatively high threshold and that strengthening the confidence, or trust, in the product - might lower this threshold.

Insta-Patch is supposed to convey vital parameters, detected by sensors in the patch, on the screen of the patch, or through an app. The connection between the patch and the app is based on a Bluetooth connection, as well as a QR-code for identification, which is not unproblematic since Bluetooth is a comparatively old technology, introduced in 1989. Although the technology has improved considerably since then, many people still associate problems with connection, for instance to speakers or headsets, with Bluetooth. According to the guideline above, a relevant question is: What happens if a medical care worker uses valuable time failing to connect, while lives or health are at stake?

The app and the patch are connected to ensure patient triage and communication of vital parameters. The app algorithm triages patients in red, yellow, and green zones, depending on their injuries. Triage is usually done manually, by assessing some defined parameters such as pulse and respiratory frequency and attaching paper tags on each patient. The algorithm does not necessarily present a trust problem, but the connotation of 'algorithm' is associated with something abstract and obscure by laypersons. Furthermore, people might distrust that the sensors in the patch read the data correctly. What if it is not attached correctly? Will it manage to take vitals correctly if there is a lot of blood spillage?

Besides the need for flawless technology, Insta-Patch must be introduced understandably and realistically to the users. This is particularly relevant in the context of an emergency because first responders (often lay people) must be knowledgeable to trust an unfamiliar (sometimes emerging) technology to assess and/or treat a potentially life-threatening condition that they are unlikely to have encountered before. Findings from the product analysis and the interviews pointed towards supplementing functionality- usability-, effectiveness- and reliability principles with intersubjective components to facilitate trust between people and organizations. When promoting and implementing a product or a service it is among others important to consider users' privacy, security, and transparency of information. Moreover, a product that users can handle with confidence and trust, is related to encouragement and inclusion.

\subsection{The designers trust kit}

Trust is subjective, relational, and contextual simultaneously, and the extent to which users trust a product or system is a consequence of both their individuality, the characteristics of the system, and the context of use. Project findings from above led to a greater human-centred design focus and changed the goal: from improving trust in one specific product shifted to developing a trust kit comprising of tools that should make it easier for designers to understand and improve trust in their projects, to "melt" trust into the designer's current ways of working. Author 1 and 2 conducted 10 semi-structured interviews with EGGs designers and 2 workshops EGGs designers, other practicing designers, peers, and supervisors. The result is a concept comprising three phases and three levels, where trust can be included in product service and systems design, shown in Figure 1 below. Figure 2 shows the 3 trust tools for the consideration phase. Each phase 'consideration', 'development' and 'implementation' includes tools. In the project, only the tools for the 'consideration' phase were developed, due to time constraints. The phases represent basic steps in the design process, the levels and tools were selected by the EGGs designers, who also decided by vote which tools they would like to use. Based on the voting three trust tools were created:

01 TRUSTSPIRATION an Instagram Account (IG)

02 A Workshop kit for consideration phase. (WS)

03 A prototype of a Design for trust app. 


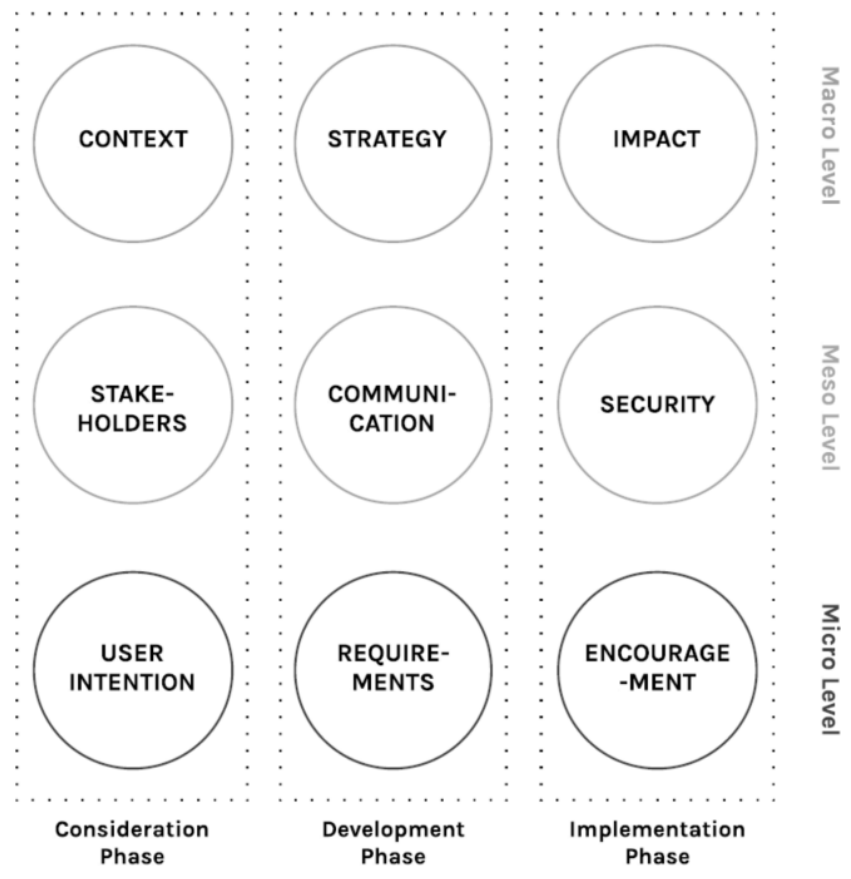

Figure 1. Trust phases and levels

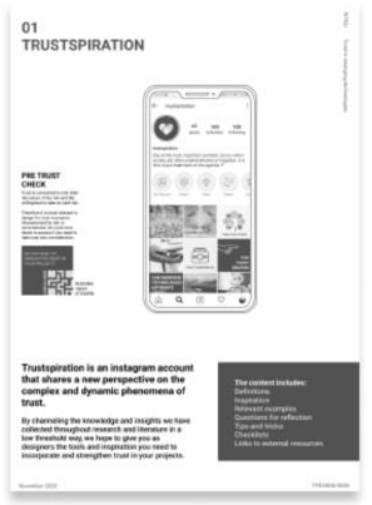

01 Trustspiration

Trustspiration is an instagram account that shares a new

perspective on the complex and dynamic phenomena of trust. By channeling the knowledge and

insights we had collected

throughout research and

literature in a low threshold way.

we hoped to give designers the

tools and inspiration they need to

incorporate and strengthen trust

in their projects.

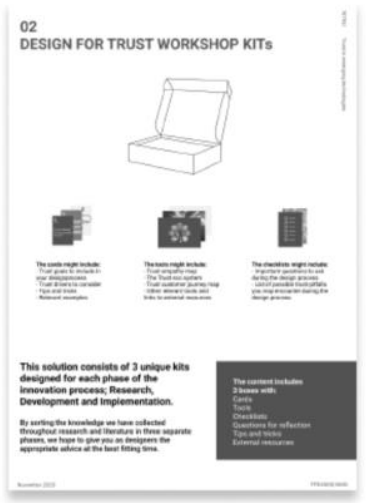

02 Design for Trust Workshop kits 1,2 and 3 (prototype)

This solution consists of 3 unique kits designed for each phase of the innovation process; Research, Development and

Implementation. By sorting the knowledge we had collected

throughout research and

literature in three separate

phases, we hoped to be able to

give designers the appropriate

advice at the best fitting time.

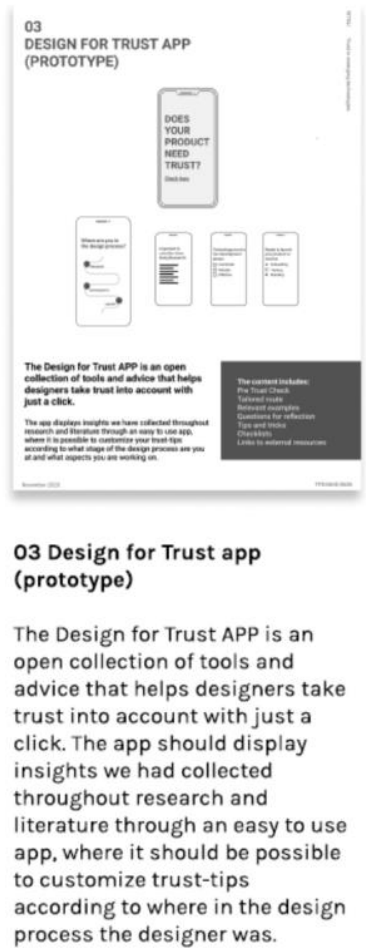

Figure 2. Suggestions for three tools in the trust kit consideration phase 


\section{CONCLUSIONS}

The exploratory research on trust and the development, the design of the trust kit presented in this paper is a work in progress and has become the topic of the master's thesis of the first two authors in spring 2021. The mentors at EGGS and NTNU agree that trust is a worthwhile subject to pursue and encourage the students in analysing the Design-for-trust-process further. Even though the project has changed its direction along the way, its connection to literature and theory has remained. This has given the students valid arguments to refine their Trust-kit concept.

The students, who are the first two authors of this article, assign the combination of theory and practice in the master's curriculum a great learning effect: "... we have learned to not be afraid of digging deep into theory, even though it might seem scary. We have been frustrated and confused at times and we have felt limited - but we have also seen that exploring theories and relating them to a project, actually opens up a world of infinite possibilities - that are highly motivational to work with. The designers and engineers, who develop and transform technologies, products, businesses or services, may express values and norms through what they make, which again might influence the behaviour of individuals or even the practices of society. We have realized that when making the choice of trusting something, one simultaneously chooses to trust the someone who created it. In this sense, what we as designers craft, becomes a mediator of trust between people or organizations."

Trust in technology is a topic that is rarely discussed in design curricula, yet it relates strongly to students' capacity building, especially in the light of emerging technologies and related roles and responsibilities of professionals. The master's course at NTNU provides students with the opportunity to explore non-technical issues and connect them with technical designer skills, thereby contributing to a more holistic engineering design education.

\section{REFERENCES}

[1] Mitchell T and Brynjolfsson E. (2017), Track how technology is transforming work, Nature, retrieved from https://www.nature.com/news/track-howtechnology-is-transforming-work1.21837, Accessed 10/09/2020.

[2] Porter M. E. and Heppelmann J. E. (2014), How smart, connected products are transforming competition, Harvard Business Review, retrieved from https://hbr.org/2014/11/how-smartconnected-products-are-transforming-competition, Accessed 10/09/2020. Probst (2020) How emerging data technologies can increase trust and transparency in fisheries, ICES Journal of Marine Science, 77: pp. 1286-1294.

[3] Radiological Society, 2019. AI improves breast cancer risk prediction, Science Daily, Retrieved from https://www.sciencedaily.com/releases/2019/12/191219090741.htm

[4] Likens S. and Kersey K. (2019), Automating trust with new technologies, Strategy + Business, TECH \& INNOVATION, retrieved from, https://www.strategy-

business.com/article/Automating-trust-with-new-technologies?gko=7e5a3, Accessed 24/10/2020.

[5] Deutsch M. (1958), Trust and suspicion, Journal of Conflict Resolution 2 (3), p. 265-279 Mayer R. C., Davis J. H., and Schoorman F. D. (1995), An Integrative Model of Organizational Trust, Academy of Management Review 20, 709-734. Corritore C. L., Kracher B., and Wiedenbeck S. (2003), On-line trust: concepts, evolving themes, a model, International Journal of Human Computer Studies, p. 737-758. Riegelsberger J., Sasse M.A. and McCarthy J.D (2005) The mechanics of trust: a framework for research and design", International Journal of Human Computer Studies, p. 381-422

[6] Mazey N. Initial trust in emerging technologies and the effect of threats to privacy, 2018, 1-16.

[7] McKnight D. H. and Chervany N. L. Trust and Distrust Definitions: One Bite at a Time, Trust in Cyberso-cieties, Springer-Verlag Berlin Heidelberg, 2001, p. 27-54.

[8] McKnight D. H., Carter M., Thatcher J. B., and Clay P. F. (2011). Trust in a specific technology: An investigation of its components and measures, ACM Transactions on Management Information Systems, 2011, Vol. 2(2), 1-25.

[9] Oxford Languages Dictionary (2020), "Black box", Retrieved from https://languages.oup.com/google-dictionaryen, Accessed 19/10/2020.

[10] Lankton N. K., McKnight D. H., and Tripp J. F. (2015), Technology, Humanness, and Trust: Rethinking Trust in Technology, Journal of the Association for Information Systems Vol. 16, Issue 10, pp. 880-918.

[11] Nielsen, Molich R., Snyder S., and Farell C., (2000). Ecommerce user experience: Trust, Nielsen 
Nor-man Group.

[12] Li Y.-M. and Yeh Y. S. (2010), Increasing trust in mobile commerce through design aesthetics, Computers in Human Behaviour 26, 2010, pp.673-684.

[13] Ebner W., Leimeister J. M., and Krcmar H., (2004), Trust in Virtual Healthcare Communities: Design and Implementation of Trust-Enabling Functionalities, Technische Universität München.

[14] Killeen J. P., Chan T. C., Buono C., Griswold W.G. and Lenert L.A., (2006), A Wireless First Responder Handheld Device for Rapid Triage, Patient Assessment and Documentation during Mass Casualty Incidents, AMIA 2006 Symposium Proceedings, pp. 429-433.

[15] Sutcliffe A. G. (2006), Trust: From Cognition to Conceptual and Design, Springer-Verlag Berlin Hei-delberg, pp. $3-17$.

[16] Li Y.-M. and Yeh Y. S. (2010), Increasing trust in mobile commerce through design aesthetics, Computers in Human Behaviour 26, pp.673-684.

[17] Ware C. (2012), Information Visualization: Perception for Design, Morgan Kaufmann.

[18] Sutcliffe A. G. (2006), Trust: From Cognition to Conceptual and Design, Springer-Verlag Berlin Hei-delberg, pp. 3 - 17.

[19] Timmons S. et al. 2008. How do lay people come to trust the Automatic External Defibrillator? Routledge, Health, Risk \& Society, Vol. 10, No. 3, June 2008, pp. 207- 220. 